\title{
POLYIMIDE CELLULOSE NANOCRYSTAL COMPOSITE AEROGELS
}

\begin{abstract}
Polyimide (PI) aerogels are highly porous solids having low density, high porosity and low thermal conductivity with good mechanical properties. They are ideal for various applications including use in antenna and insulation such as inflatable decelerators used in entry, decent and landing operations. Recently, attention has been focused on stimuli responsive materials such as cellulose nano crystals (CNCs). CNCs are environmentally friendly, bio-renewable, commonly found in plants and the dermis of sea tunicates, and potentially low cost. This study is to examine the effects of CNC on the polyimide aerogels. The CNC used in this project are extracted from mantle of a sea creature called tunicates. A series of polyimide cellulose nanocrystal composite aerogels has been fabricated having 0-13 wt of CNC. Results will be discussed.
\end{abstract}




\title{
Polyimide Cellulose Nanocrystal Composite Aerogels
}

\author{
Baochau N. Nguyen, OAI \\ Mary Ann B. Meador, NASA Glenn \\ Stuart J. Rowan, CWRU \\ Elvis Cudjoe, CWRU \\ Anna Sandberg, Summer Intern
}




\section{What are aerogels?}

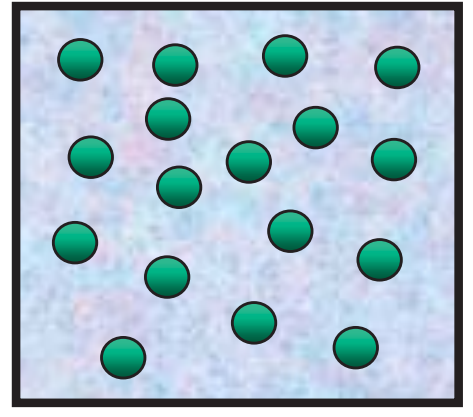

Sol

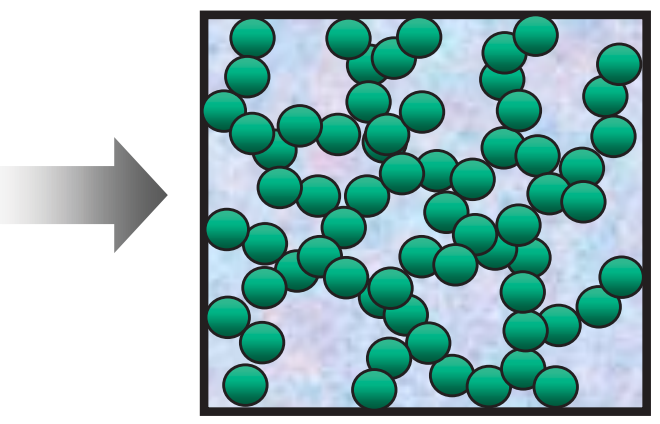

Gel

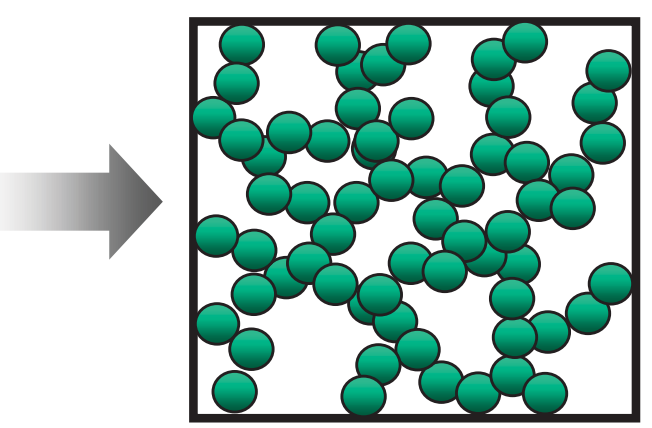

Aerogel

- Highly porous solids made by removing liquid portion of a wet gel

- Nanometer scale pore size $(10-40 \mathrm{~nm})$

- High porosity (> 90\%) and surface area $\left(200-650 \mathrm{~m}^{2} / \mathrm{g}\right)$

- Low density $\left(<0.3 \mathrm{~g} / \mathrm{cm}^{3}\right)$

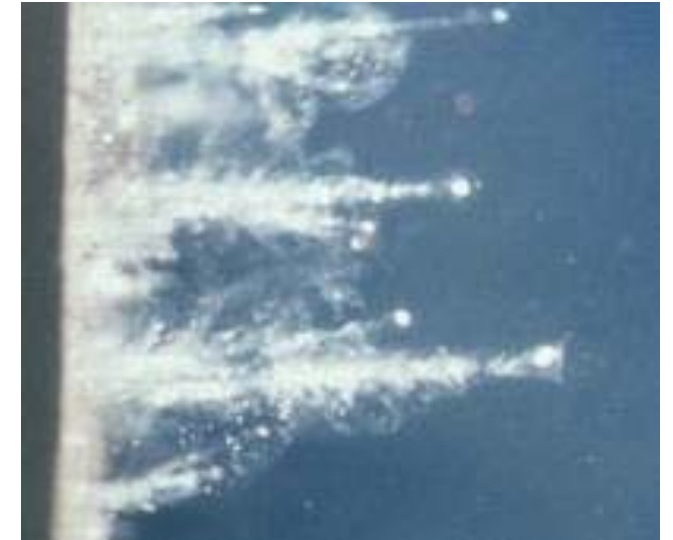

Cosmic dust collector Stardust Mission

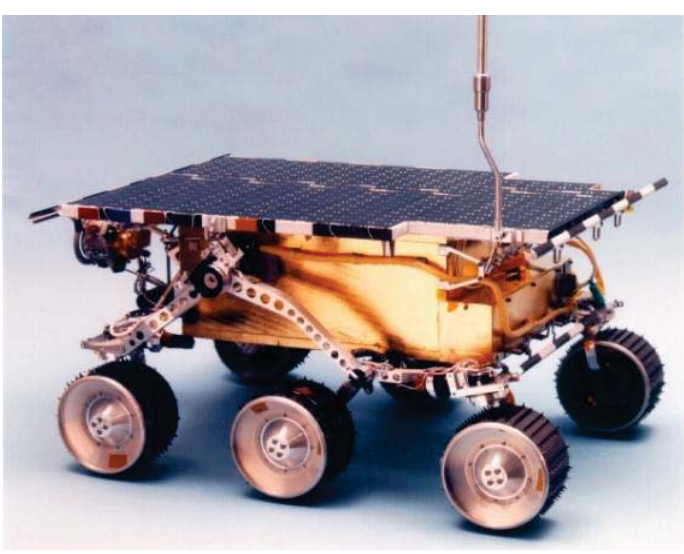

Rover battery insulation 


\section{Possible applications}

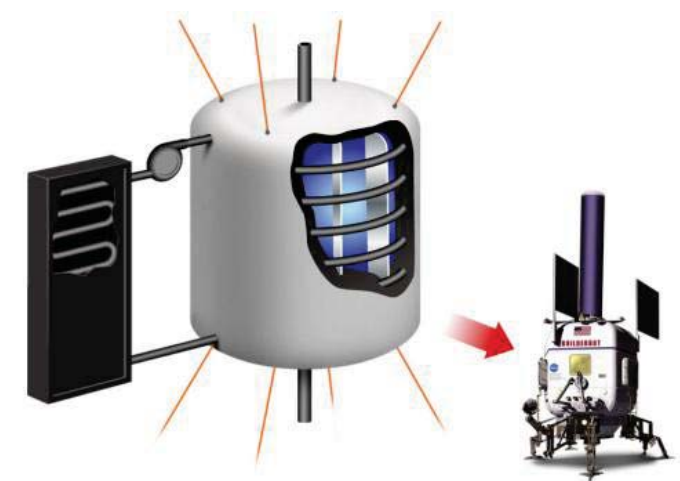

Cryotank Insulation

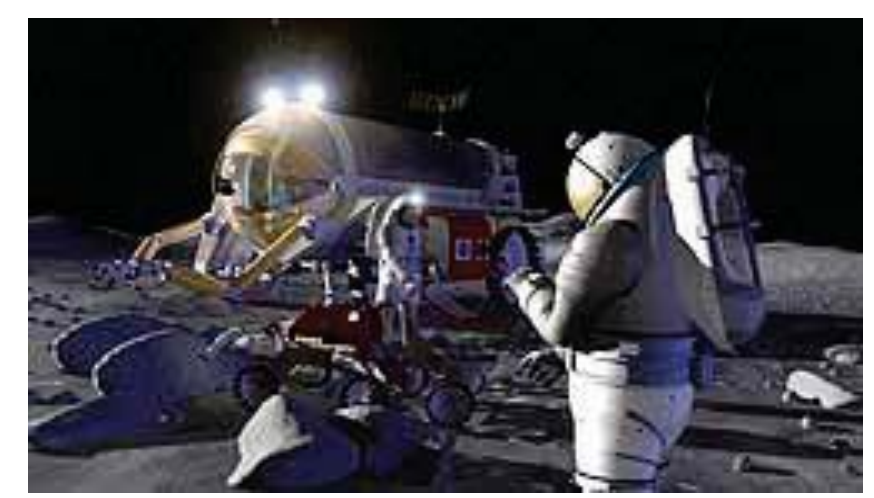

Insulation for EVA suits, habitats and rovers
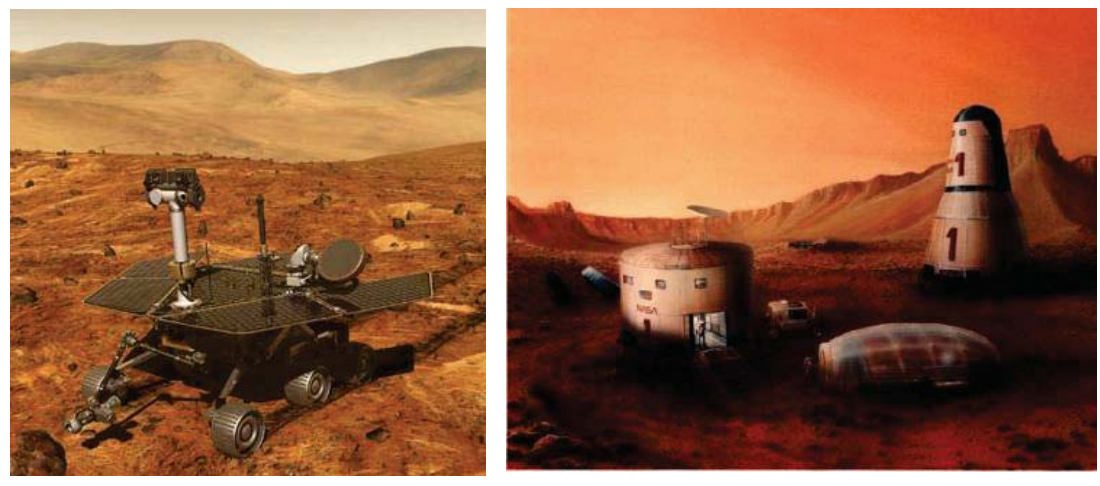

Ultra-lightweight, multifunctional structures for habitats, rovers

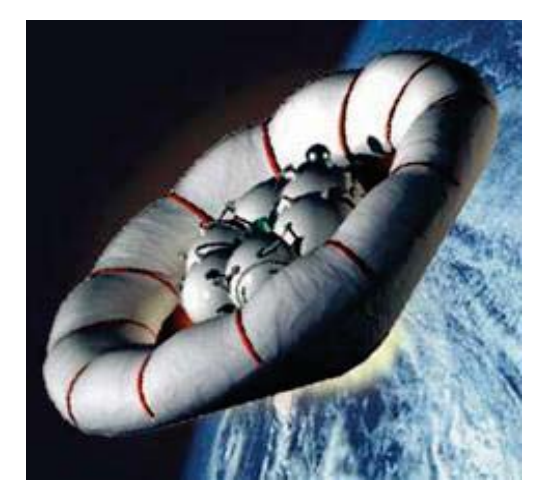

Inflatable Decelerator 


\section{Aromatic polyimide aerogels}

- Low thermal conductivity

- High temperature stability (short term)

- Moisture resistance depending on backbone chemistry

- Improved mechanical properties

- Flexible and durable

- Easy to manufacture into thin film

Objective:

- Crosslinked polyimide aerogels

- Incorporation of a nano filler to further enhance physical and mechanical properties - cellulose nanocrystals (CNCs)
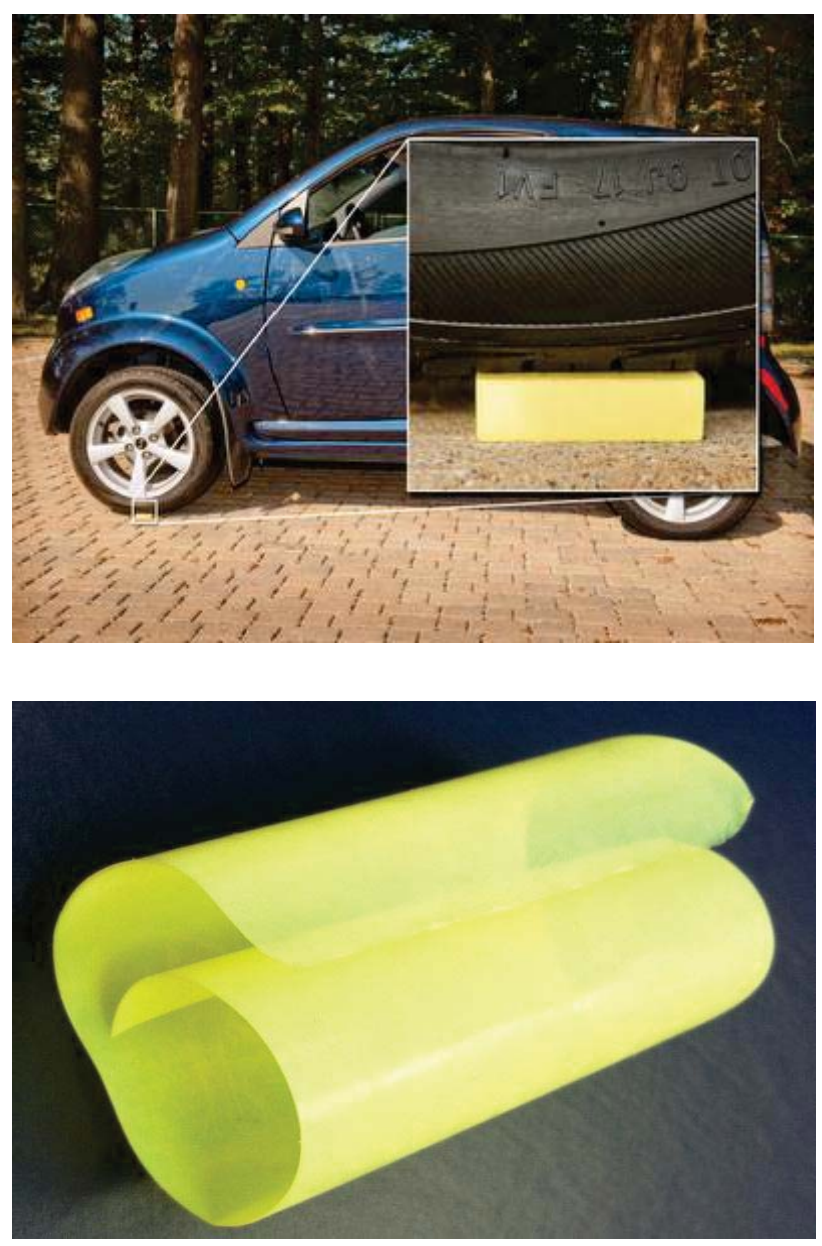


\section{Cellulose nanocrystals (CNCs)}

- Bio-renewable, potentially low cost

- Exist in most plants and can be found in dermis of some mammals

- Can easily be modified with different charge densities or functionalities

- make them compatible with different solvents and polymers

- Possibility to gain further mechanical strength and/or stimuli responsive behaviors

- Flexible in water, rigid in air, etc

- CNC extracted from the mantles of a sea creature called a tunicate (tw-CNC) with aspect ratio of 80:1
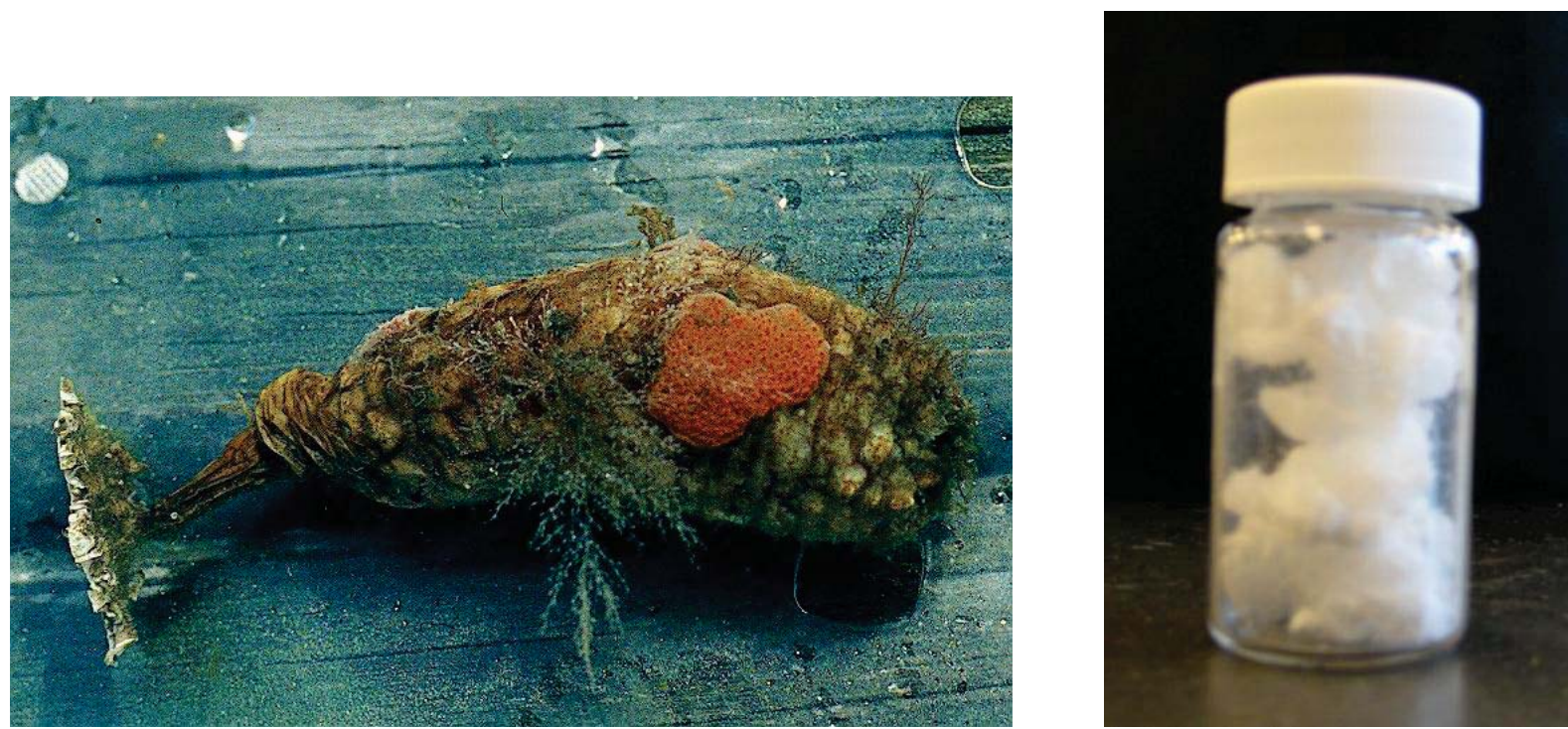


\section{Monomers used}

Diamines<smiles>Cc1cc(N)ccc1-c1ccc(N)cc1C</smiles>

2,2'-Dimethylbenzidine (DMBZ)

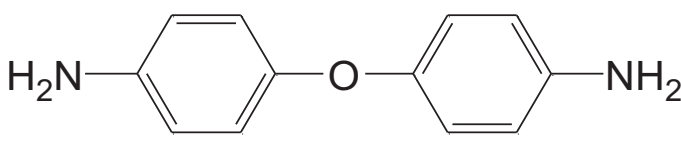

4,4'-Oxydianiline (ODA)

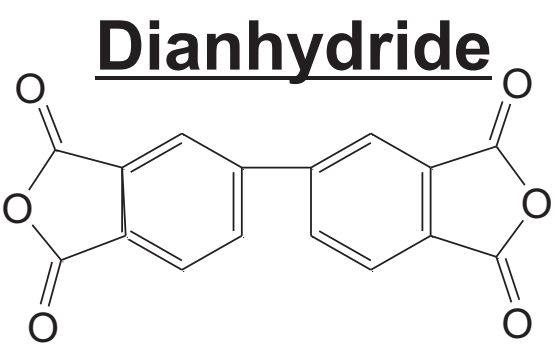

3,3',4,4'-Diphenyl tetracarboxylic dianhydride (BPDA)

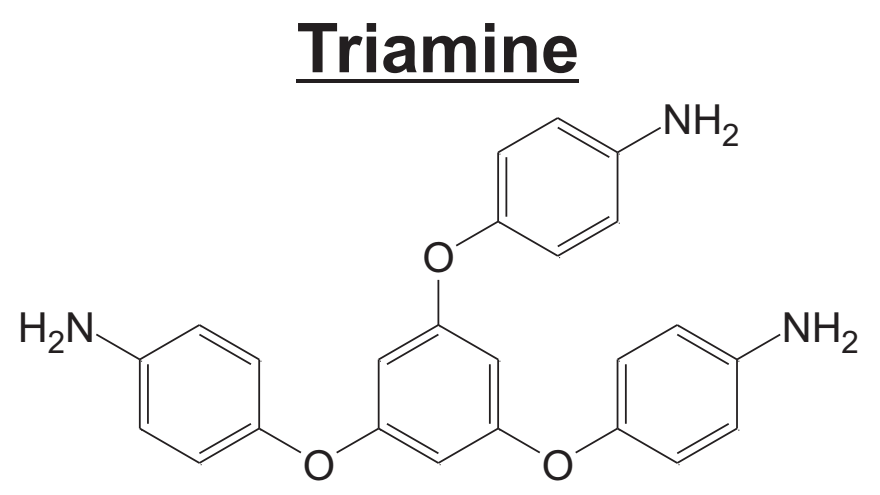

1,3,5-Triaminophenoxy benzene (TAB)

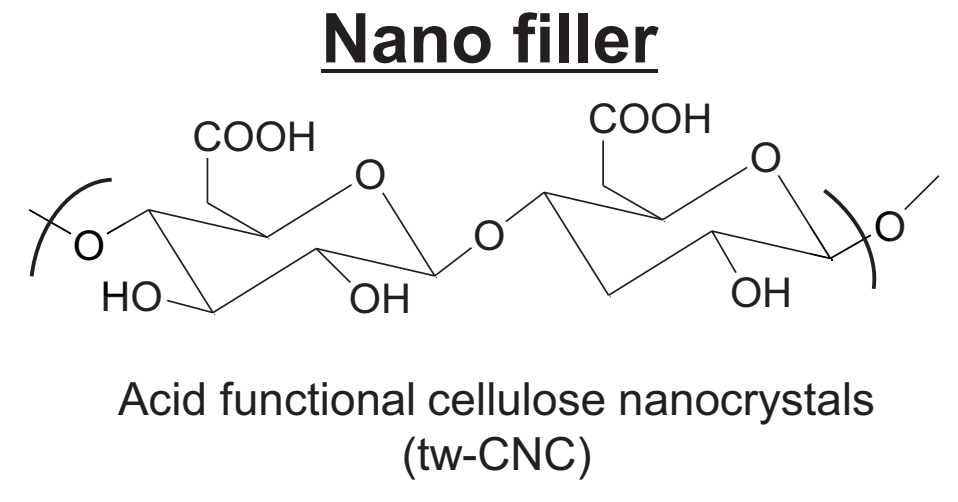

Solvent<smiles>CN1CCCC1=O</smiles>

$\mathrm{N}$-methyl-2-pyrolidiinone (NMP)

\section{Water Scavenger}<smiles>CC(=O)OC(C)=O</smiles>

Acetic anhydride

(AA)

\section{Catalyst}

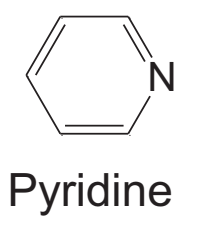

(Py) 


\section{Chemical imidization at room temperature}

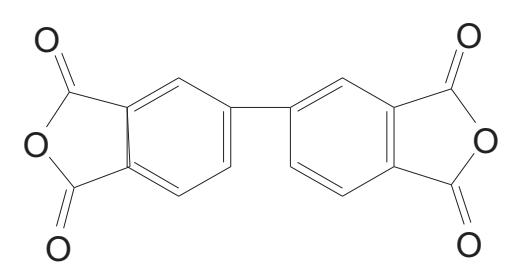

$$
\mathrm{H}_{2} \mathrm{~N}-\mathrm{R}-\mathrm{NH}_{2}
$$

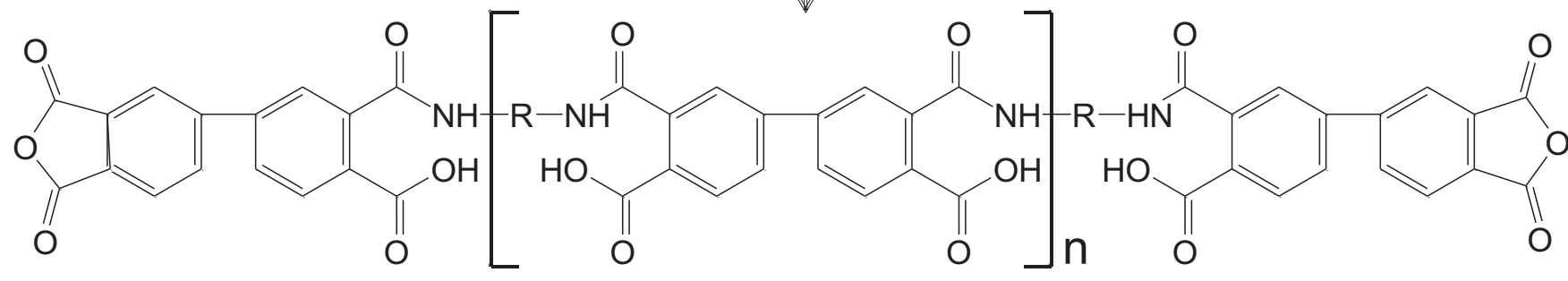

TAB, AA, Py $\sqrt{ }$ Chemical Imidization

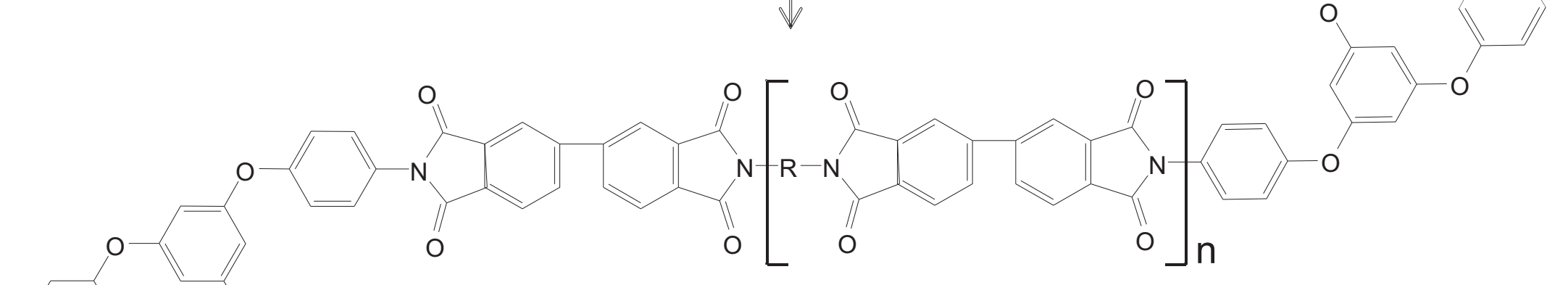




\section{Compositions}

Concentration of total solids in solution:

- Solid concentration $=(\mathrm{g}$ total solid $) /(\mathrm{g}$ solution $)=7.5 \mathrm{wt} \%$

- Total solid weight $=\mathrm{g}$ polymer $+\mathrm{g}$ CNC

- Repeat units, $\mathrm{n}=30$

Diamine variation on the backbone:

- $100 \mathrm{~mol} \%$ DMBZ

- $100 \mathrm{~mol} \%$ ODA

CNC loading:

- $0-13.33 \mathrm{wt} \%$ of total solid

- $\mathrm{CNC}$ concentration $=(\mathrm{g} \mathrm{CNC}) /(\mathrm{g} \mathrm{CNC}+\mathrm{g}$ polyimide $)$ 


\section{NMRs and TGAs: Evidence of CNC in the matrix}
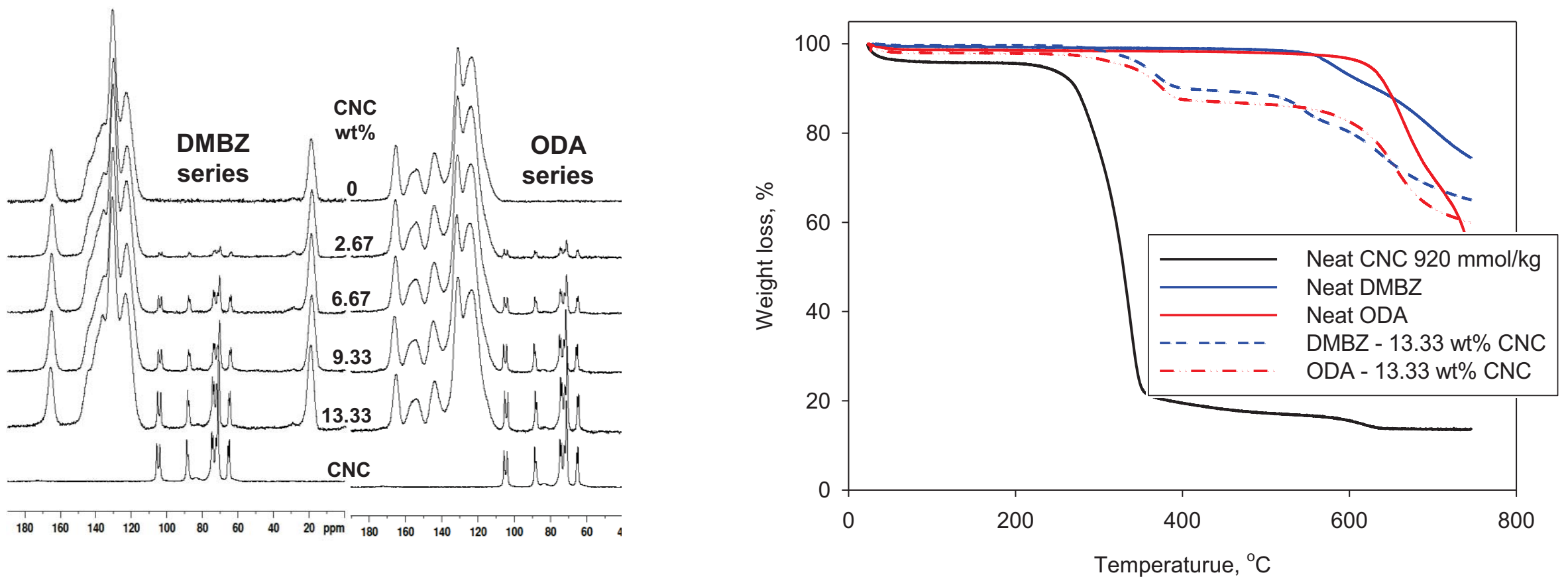

- $\mathrm{CNC}$ can be detected using NMR

- Can be quantified by TGA

- Same wt. loss in both sets of aerogels

- Low calculated CNC wt loss than formulated $\rightarrow$ interaction between $\mathrm{CNC}$ and PIs

- Higher $\mathrm{T}_{d} \mathrm{~s}$ of CNC $\rightarrow$ effect of aromatic PIs

- Lower $\mathrm{T}_{\mathrm{d}} \mathrm{s}$ of PIs $\rightarrow$ effect of aliphatic CNC

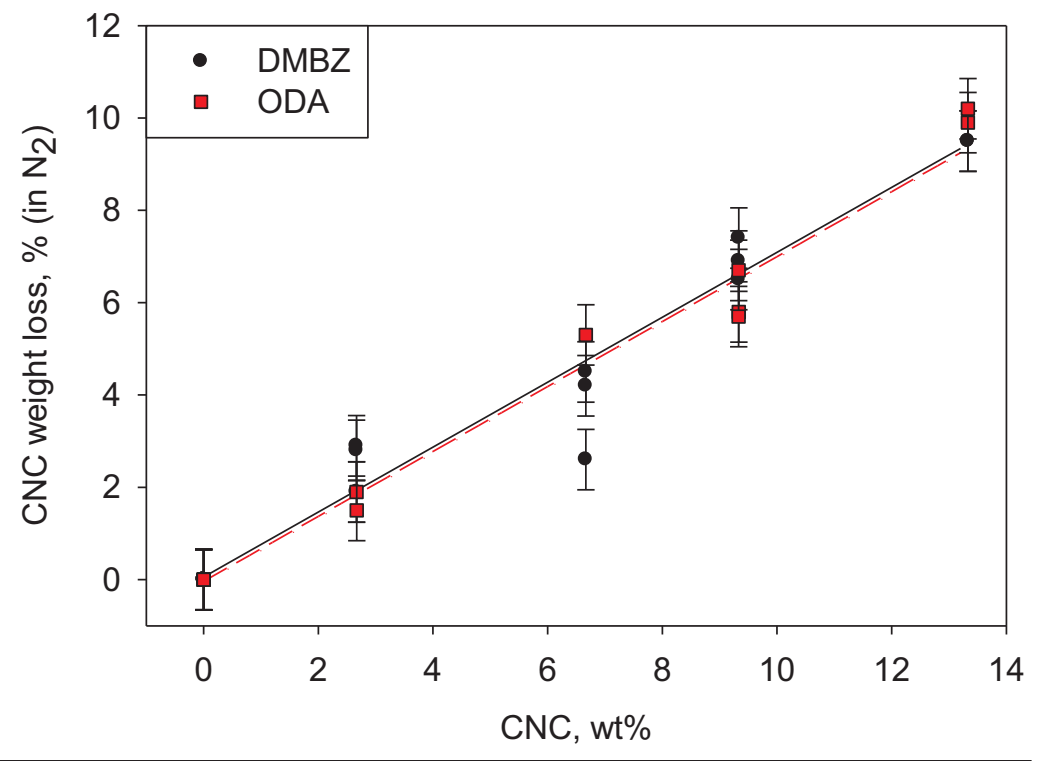




\section{Scanning Electron Micrographs (SEMs): No difference in pore structure}
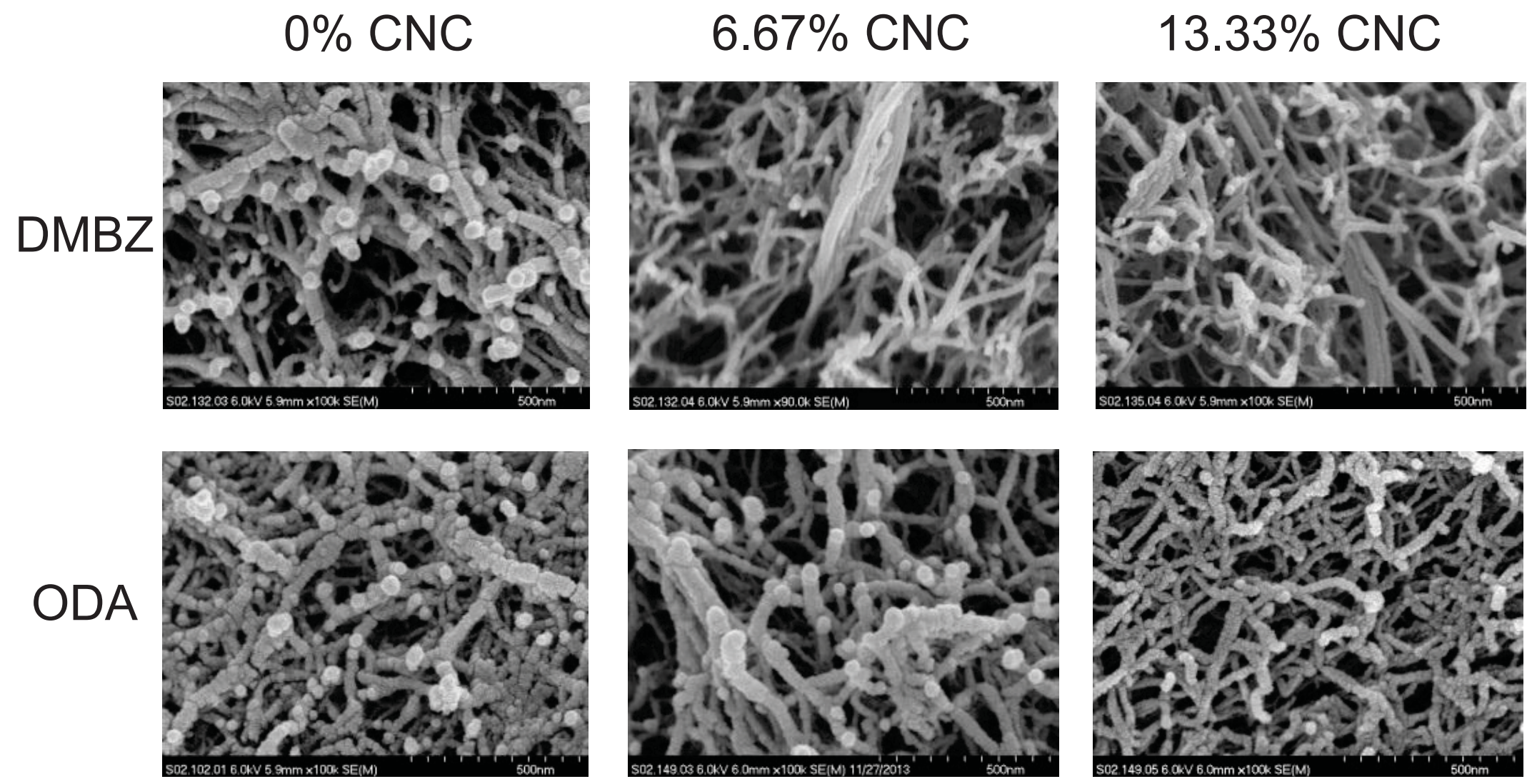

Aerogels with DMBZ in the backbone are more porous 


\section{Incorporation of CNC improves physical properties}
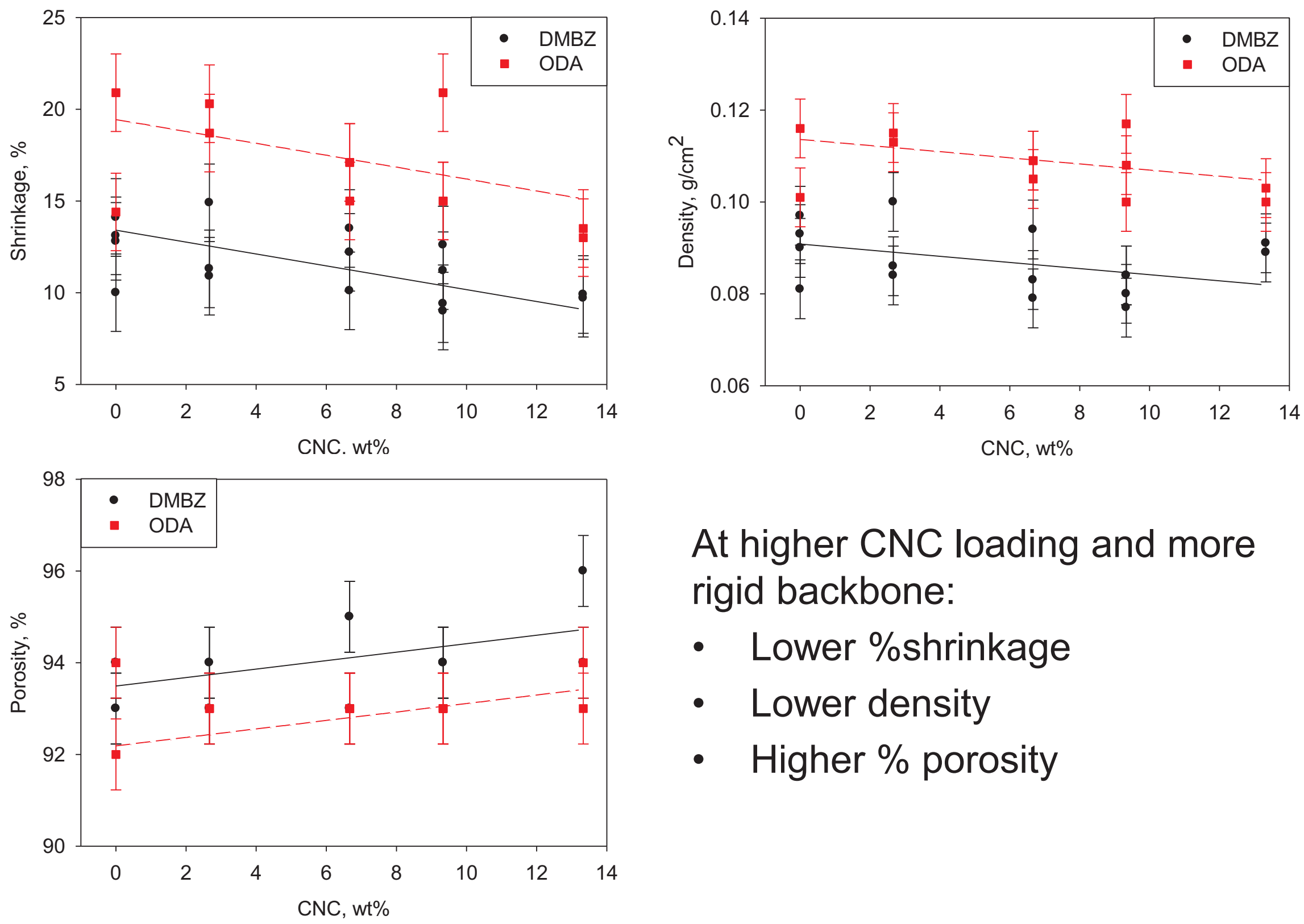

At higher CNC loading and more rigid backbone:

- Lower \%shrinkage

- Lower density

- Higher \% porosity 


\section{Brunauer-Emmet-Teller (BET) surface area}

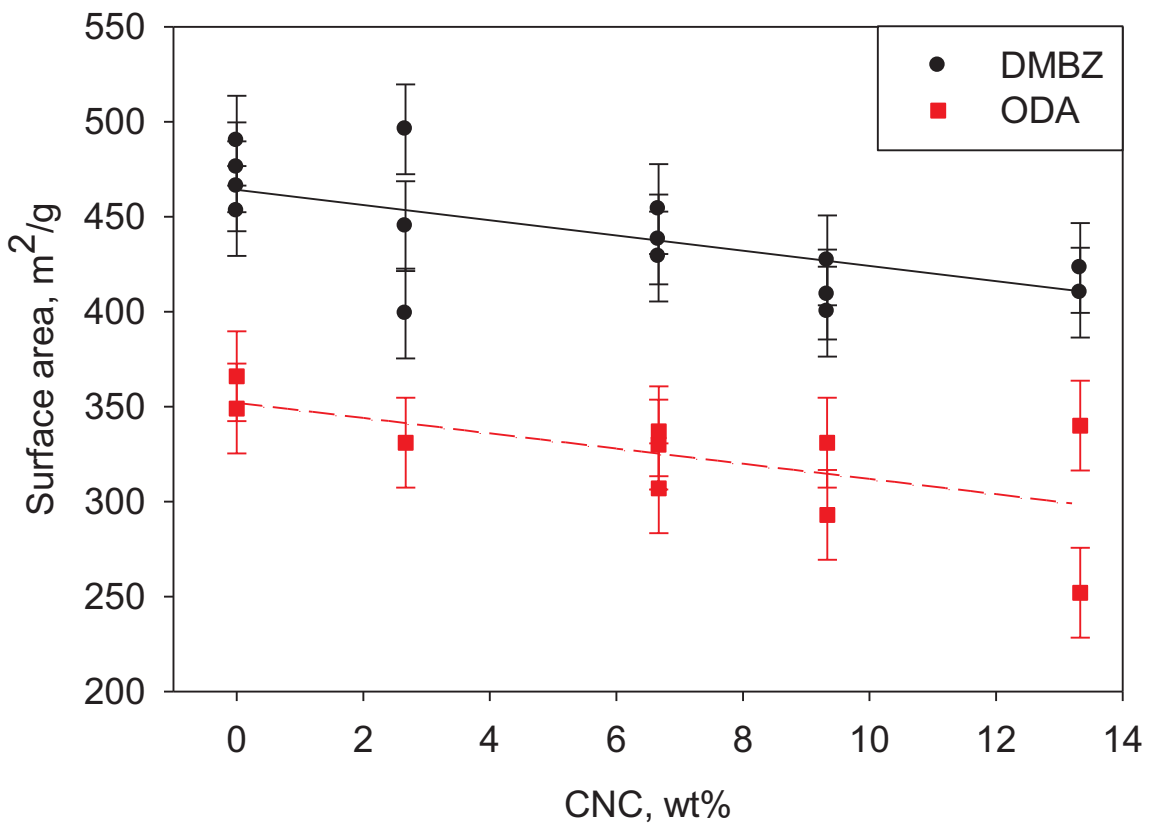

At higher CNC loading:

- Lower BET surface area

- Larger pore diameter

- Wider pore diameter distribution DMBZ vs. ODA:

- Higher pore volume

- Narrower pore diameter distribution
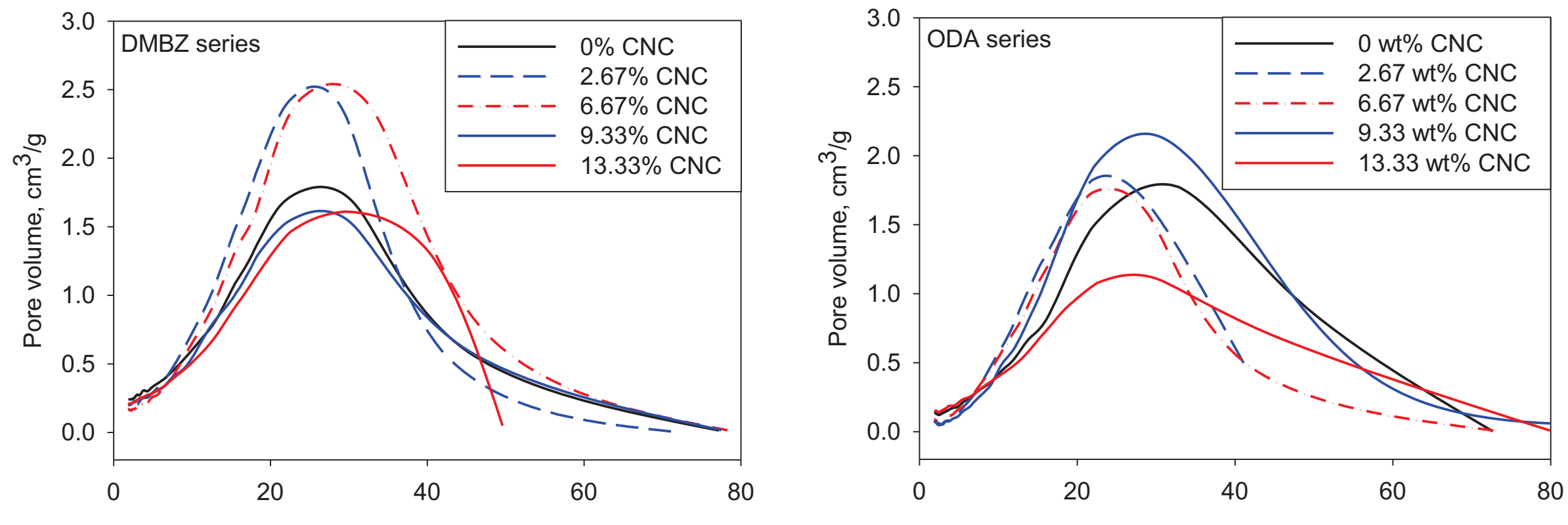


\section{Improves mechanical properties at high $\mathrm{CNC}$ loading}
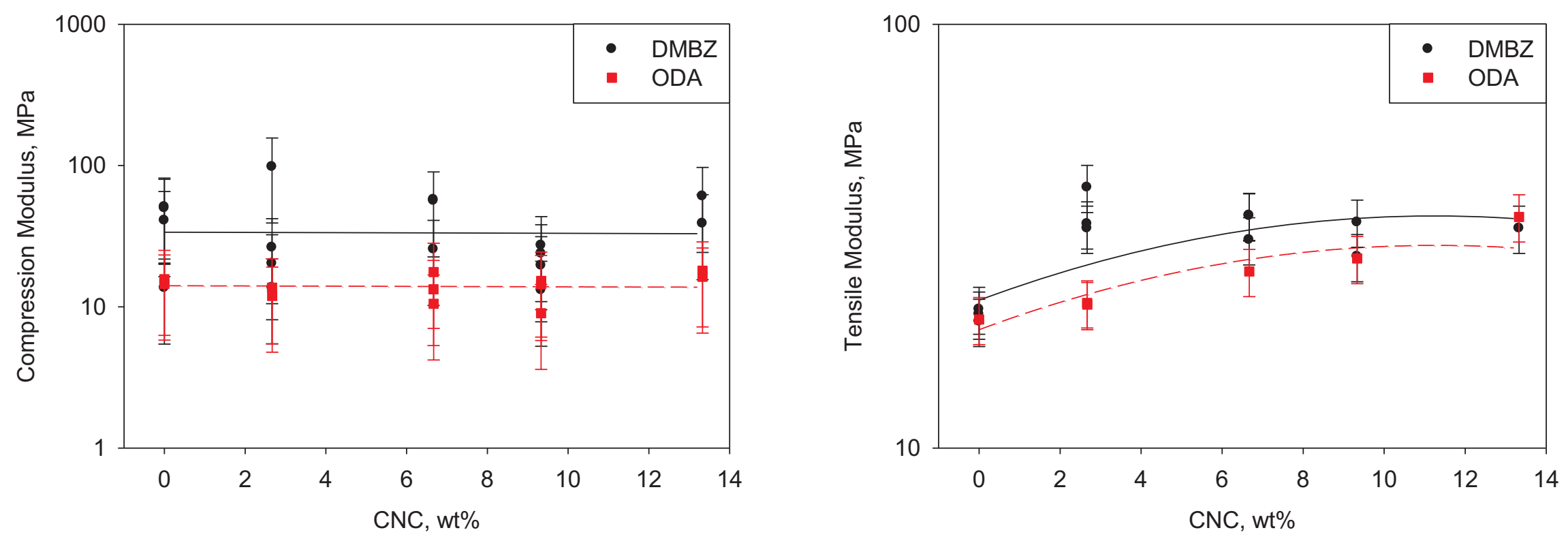

Higher CNC loading:

- $\quad$ Slight decrease in compression modulus (density dependent)

- Higher tensile modulus

- Lower \% elongation

More rigid backbone:

- Higher modulus (density independent)

- Lower \% elongation

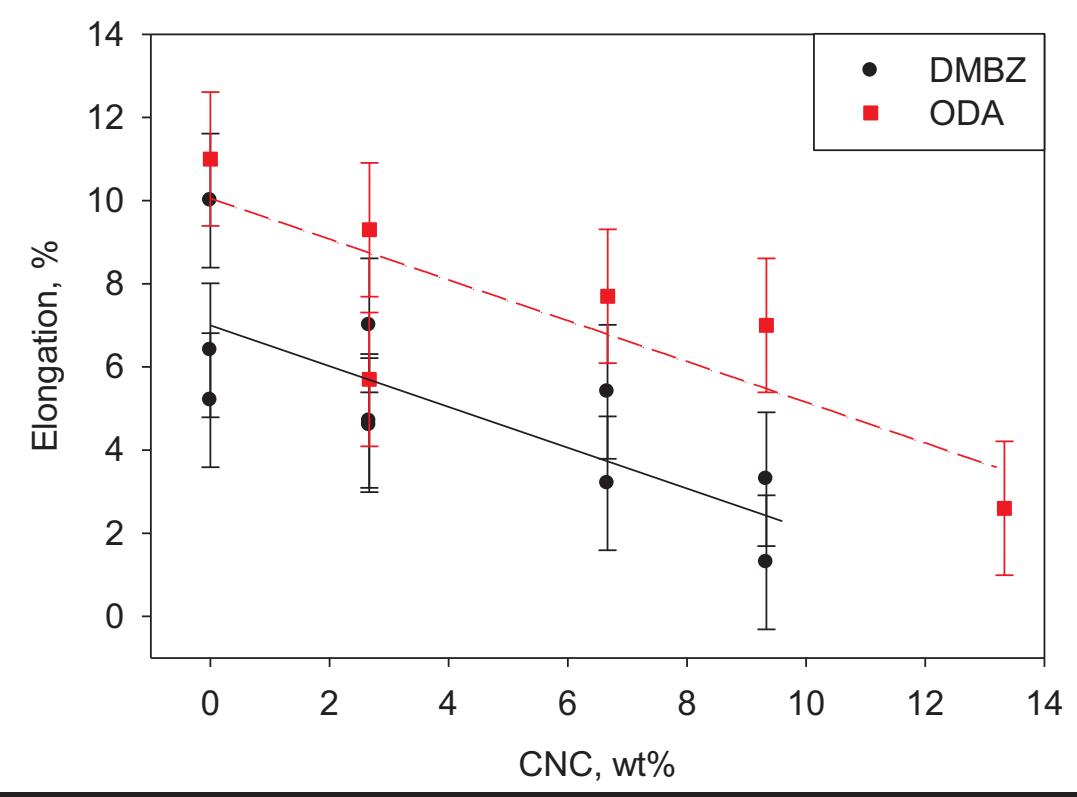




\section{Aging Study: CNC diminishes at $200^{\circ} \mathrm{C}$}
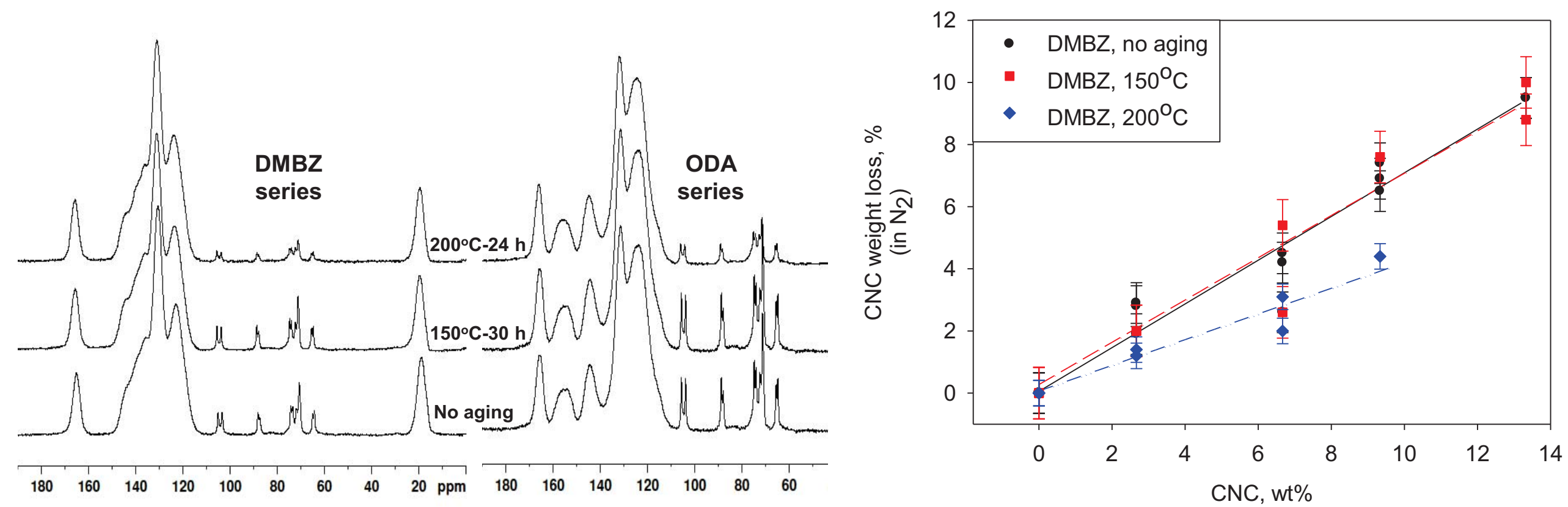

- Aged at $150^{\circ} \mathrm{C}$ for $30 \mathrm{~h}$ and $200^{\circ} \mathrm{C}$ for $24 \mathrm{~h}$

- CNC is stable at $150^{\circ} \mathrm{C}$ for $30 \mathrm{~h} \rightarrow$ no wt. loss during the aging period

- CNC starts to decompose at $200^{\circ} \mathrm{C}$

$\rightarrow$ Slowly diminishes over $24 \mathrm{~h}$ of aging

$\rightarrow$ Higher decomposition rate at higher CNC content (less PI in the matrix composite)

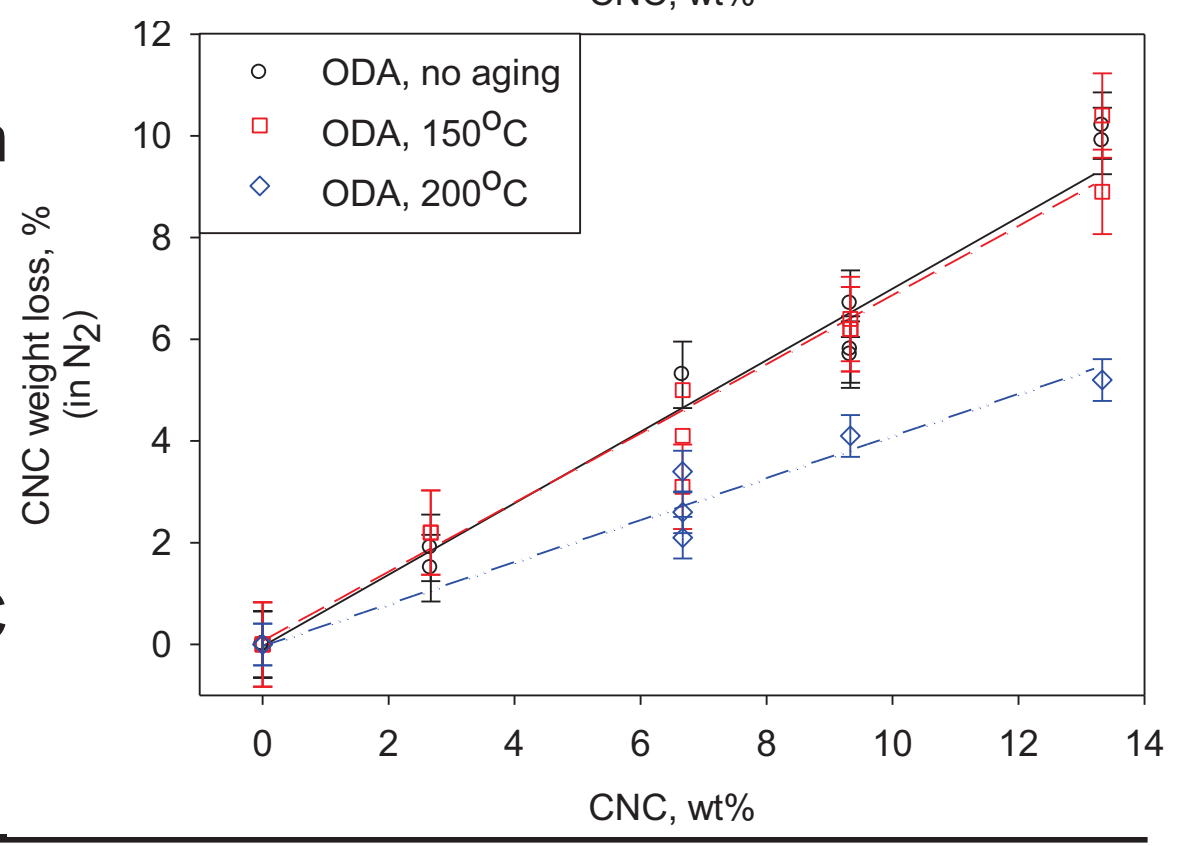




\section{Aging study: higher CNC loading reduces shrinkage and lowers density}
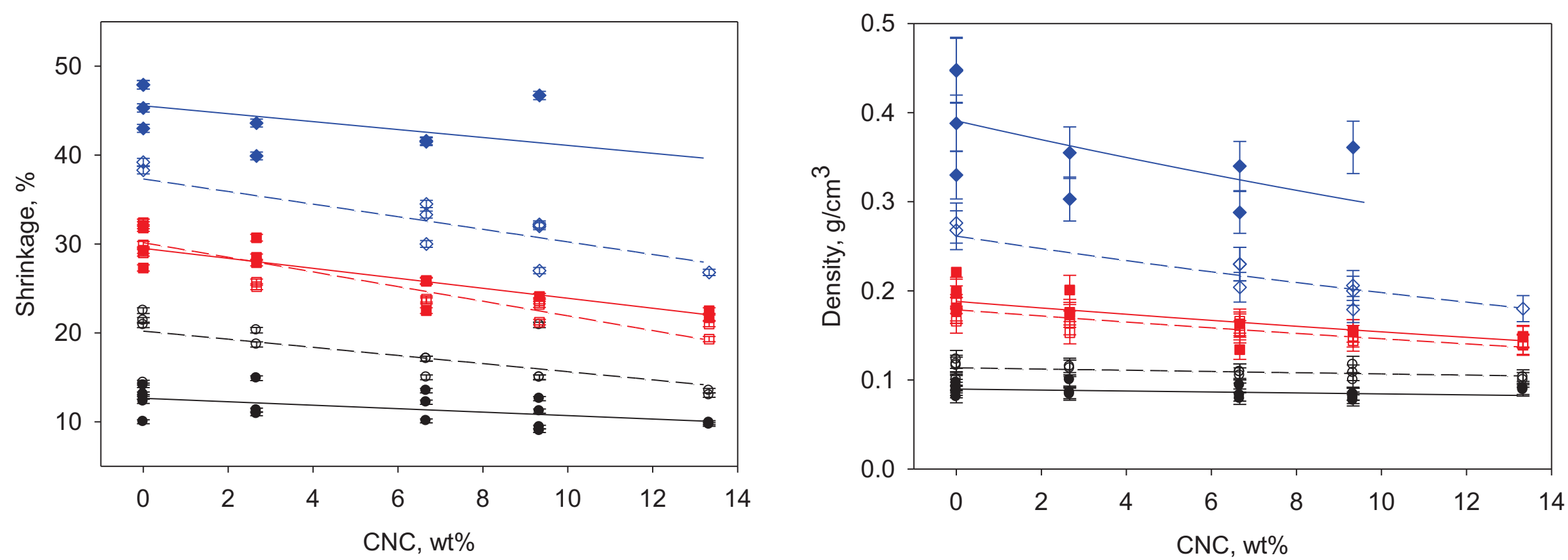

- At higher CNC content $\rightarrow$ lower shrinkage and density

- At elevated temperature

$\rightarrow$ higher shrinkage and higher density

$\rightarrow$ Higher shrinkage and density for DMBZbase aerogels

- $\quad \mathrm{DMBZ}$, no aging

- ODA, no aging

- $\quad \mathrm{DMBZ}, 150^{\circ} \mathrm{C}$

- $\mathrm{ODA}, 150^{\circ} \mathrm{C}$

- DMBZ, $200^{\circ} \mathrm{C}$

$\diamond \quad \mathrm{ODA}, 200^{\circ} \mathrm{C}$ 


\section{Conclusion}

With the incorporation of $\mathrm{CNC}$ :

- Good CNC-polyimide interaction

- Retained pore size and structural integrity

- Improved both physical and mechanical properties

At higher CNC loading:

- Lower shrinkage and density (both at RT and elevated temperatures)

- Higher porosity

- Lower BET surface area

- Little change in compression modulus

- Higher tensile modulus

- Lower \% elongation

More rigid backbone, DMBZ vs. ODA:

- Better physical properties at room temperature

- Physical properties suffered more at elevated temperature 


\section{Acknowledgements}

\section{Collaborators}

Dr. Mary Ann B. Meador, NASA Glenn Research Center

Prof. Stuart J. Rowan, Case Western Reserve University

Elvis Cudjoe, Graduate Student, CWRU

\section{Contributors}

Anna Sandberg, LERCIP 2013 Summer Intern

Dr. Haiquan Guo, OAI

Daniel Scheiman, OAI

Linda McCorkle, OAI

Dan Haas, NASA Glenn 